\title{
Rescue Maneuver of Migrated Coil Using the ERIC Device after Previous Attempts with Conventional Stentrievers
}

\author{
Miguel Schüller-Arteaga, $\mathrm{MD}^{1}$, Jorge Galván-Fernández, $\mathrm{PhD}^{1}$, Paloma Jiménez-Arribas, $\mathrm{MD}^{2}$, \\ Leonor Nogales-Martin, $\mathrm{MD}^{3}$, Carlos Rodríguez-Arias, $\mathrm{PhD}^{2}$, Mario Martínez-Galdámez, $\mathrm{MD}^{1}$ \\ ${ }^{1}$ Interventional Neuroradiology/Endovascular Neurosurgery, Hospital Clínico Universitario de Valladolid, Valladolid, Spain \\ ${ }^{2}$ Department of Neurosurgery, Hospital Clínico Universitario de Valladolid, Valladolid, Spain \\ ${ }^{3}$ Department of Intensive Care, Hospital Clínico Universitario de Valladolid, Valladolid, Spain
}

Coil prolapse or migration is a rare but potentially serious complication that may occur during aneurysm embolization, with no standard management currently described. Here we describe our experience with the Embolus Retriever with Interlinked Cages (ERIC) device ${ }^{\circledast}$ (Microvention, Aliso Viejo, CA, USA) for the retrieval of prolapsed or migrated coils in a case series and Flow-Model analysis. First, a retrospective review was performed using our institution database for patients in which coil prolapse or migration occurred during aneurysm embolization, and data was collected and analyzed. Second, an in vitro Flow-Model analysis was performed comparing the ERIC device ${ }^{\oplus}$ with other stent retrievers for coil retrieval. In 2 cases, the ERIC device ${ }^{\oplus}$ successfully retrieved the displaced coil from intracranial circulation in 1 pass, after failure with other devices. In the Flow-Model, again the ERIC device ${ }^{\oplus}$ achieved success for retrieving a detached coil, whereas 2 other different stent retrievers failed to capture the coil after 2 attempts. The ERIC device ${ }^{\oplus}$ appears to be a safe and effective tool for retrieving a prolapsed or migrated coil from the intracranial circulation.

Key Words: Therapeutic embolization; Humans; Stents; Intracranial aneurysm; Retrospective studies; Thrombectomy

\section{INTRODUCTION}

Since the publication of large trials demonstrating the safety and efficacy of endovascular coiling embolization in ruptured intracranial aneurysms, it has become standard care at most centers as the initial treatment strategy.

However, with increased use of coils in progressively complex ruptured aneurysm cases, due to the development of balloon-assisted and stent-assisted techniques, an increase in coiling-related complications has also been observed. ${ }^{2}$
Among these, coil prolapse and coil migration constitute a rare but potentially serious complication, since if not correctly managed it can lead to thrombus formation and vessel occlusion resulting in cerebral infarction, even in a delayed fashion. ${ }^{3}$ Its reported incidence rate ranges from $2 \%$ to $6 \%$, which has not significantly changed over time, and consequences have ranged from asymptomatic to occlusion of major arteries, potentially resulting in large territory infarcts. ${ }^{4}$

Different endovascular techniques

\section{Correspondence to:}

Miguel Schüller-Arteaga, MD

Interventional Neuroradiology/

Endovascular Neurosurgery, Hospital

Clínico Universitario de Valladolid,

Av. Ramón y Cajal 3, Valladolid 47003, Spain

Tel: +34603 490465

Fax: +34 983257511

E-mail:dr.schuller@gmail.com

Received: January 27, 2021

Revised: March 24, 2021

Accepted: May 11, 2021
Copyright $\odot 2021$ Korean Society of Interventional Neuroradiology

This is an Open Access article distributed under the terms of the Creative Commons Attribution Non-Commercial License (http://creativecommons.org/licenses/by-nc/4.0) which permits unrestricted non-commercial use, distribution, and reproduction in any medium, provided the original work is properly cited.

pISSN 2093-9043 eISSN 2233-6273 
have been described for managing an intraprocedural coil prolapse or migration: stent placement, microwires, the Alligator Retrieval device, Merci device, snare device, stent retrievers (SR), and even microsurgical extraction, with no standard or truly effective strategy described to our knowledge. . $^{5-10}$

The Embolus Retriever with Interlinked Cages (ERIC) device $^{\circledast}$ (Microvention, Aliso Viejo, CA, USA) (Fig. 1A, B) is a new generation stentriever constructed with an interlinked cage technology, designed to have a high intraluminal metal coverage and less vessel wall contact, theoretically allowing for an atraumatic thrombectomy and better thrombus entrapment. Here we describe our experience using the ERIC device (ED) to recapture a migrated coil, after failed attempts with other stentrievers, as well as an in vitro demonstration of the efficacy of the device and the reasoning for it to be used as a first approach in cases of displaced or migrated coils.

\section{MATERIALS AND METHODS}

Our institutional review board approved this study, and the informed consent was waived.

Clinical and radiological data were retrospectively reviewed from our institutional database for patients who underwent an aneurysm embolization procedure in our institution between January 2017 and December 2019. From this cohort, patients who presented coil prolapse or migration during or after endovascular embolization were identified, in whom at least 1 retrieval attempt was performed. Coil prolapse or migration was defined as a coil coming out of the aneurysmal sac after having been released, either partially (prolapse) or completely (migration). Procedural data was collected, which included coil size, devices employed, and number of retrieval attempts.

Additionally, an in vitro analysis was performed in a tubular, multicurved segment, silicone flow model of the carotid artery, comparing the ED with other well-known stent retrievers on the effectiveness of coil retrieval (Table 1). For this, up
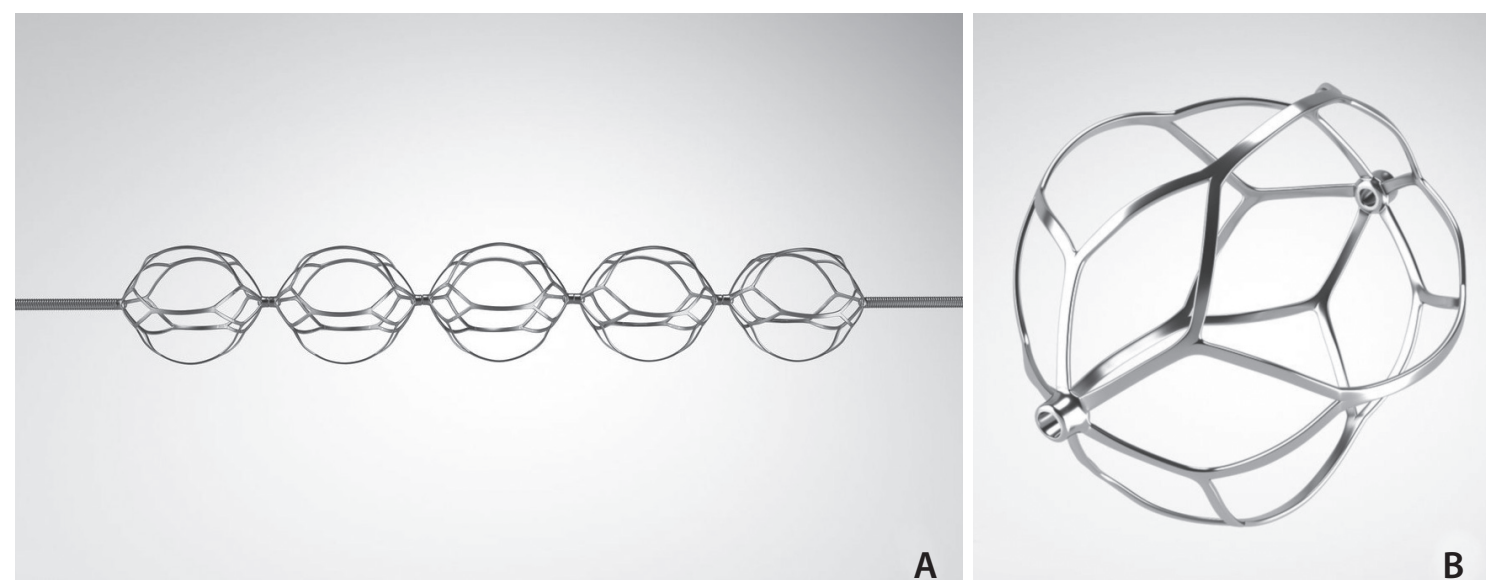

A

B

Fig. 1. Embolus Retriever with Interlinked Cages (ERIC) device design. (A) Construction of the device with interlinked spherical cages fixed on a pusher wire. The design of the device results in limited contact points with the vessel wall which can potentially reduce vascular trauma. (B) Magnified view of a single cage. Image from ERIC device ${ }^{\circledast}$ (Microvention, Aliso Viejo, CA, USA).

Table 1. Devices used, and number of attempts, for the in vitro analysis

\begin{tabular}{lcccc}
\hline Stent retriever & Size & Attempts & Success (\%) & Mesh interaction* \\
\hline Trevo XP ProVue & $6 \times 25 \mathrm{~mm}$ & 2 & 0 & No \\
Embotrap II $^{\oplus}$ & $5 \times 33 \mathrm{~mm}$ & 2 & 0 & Yes \\
ERIC device $^{\oplus}$ & $6 \times 35 \mathrm{~mm}$ & 2 & 100 & Yes \\
\hline
\end{tabular}

Trevo XP ProVue ${ }^{\oplus}$ (Stryker, Kalamazoo, MI, USA), Embotrap $\|^{\circledast}$ (Johnson \& Johnson, New Brunswick, NJ, USA), ERIC device ${ }^{\oplus}$ (Microvention, Aliso Viejo, CA, USA).

*Coil entrapment with stentriever cells. 
to 2 attempts were made to retrieve a detached coil (Target ${ }^{\oplus}$ $7 \mathrm{~mm} \times 15 \mathrm{~cm}, 360$ Standard; Stryker, Kalamazoo, MI, USA), employing 1 of 3 stent retrievers (Table 1), either a closed cell SR (Trevo XP ProVue ${ }^{\oplus}$; Stryker), a different articulated coil (Embotrap 2; Johnson \& Johnson, New Brunswick, NJ, USA), or the ERIC device ${ }^{\circledast}$. The technique consisted of detaching a different coil inside the flow model for each device, and then trying to retrieve it with the stent retriever, without using an intermediate catheter or pinning the coil.

\section{RESULTS}

After excluding aneurysms treated by stent-assisted coiling or a flow diverter from the analysis, a total of 130 patients were found to have been treated by coiling or balloon-assisted coiling embolization for intracranial aneurysms between January 2017 and December 2019 at our institution. Of these, in $2(1.5 \%)$ patients a coil prolapse or migration occurred, which were retrieved by end of the procedure. Both cases presented as a subarachnoid hemorrhage $(S A H)$ secondary to an anterior communicating artery (ACOA) ruptured widenecked aneurysm, treated with balloon-assisted coiling.

\section{Case 1}

A middle-aged patient presented to the emergency department with a headache due to a FISHER II subarachnoid hemorrhage, with H\&H I and WFNS II scores. The patient was diagnosed with a ruptured ACOA aneurysm, and emergent embolization was performed (Fig. 2A). During embolization, a coil migrated into the A2 segment (Fig. 2B). After administering a loading dose of IV aspirin, we tried an initial retrieval attempt with an Embotrap ${ }^{\circledR}$ stentriever, and the coil then migrated into the left M3 segment. Afterward, a $3 \times 20$ mm Eric device was deployed through a 0.017 inch microcatheter (Stryker ${ }^{\circledast}$ SL-10) (Fig. 2C), successfully recapturing the migrated coil in 1 pass (Fig. 2D).
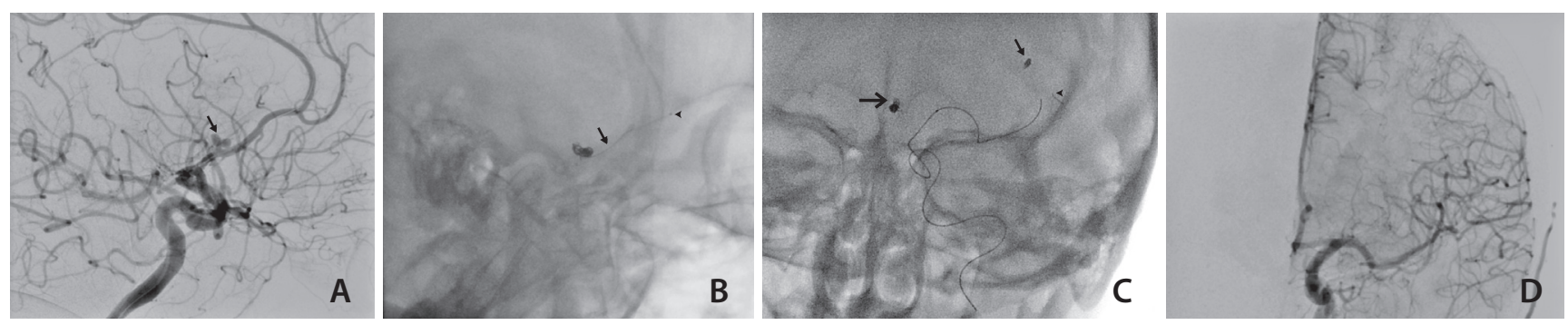

Fig. 2. (A) The aneurysm morphology can be seen prior to embolization (small arrow). (B) Partially migrated coil (small arrow) can be seen prior to first attempt with Embotrap ${ }^{\circledast}$ (Johnson \& Johnson, New Brunswick, NJ, USA). Stryker ${ }^{\circledR}$ SL-10 (Kalamazoo, MI, USA) is navigated past the migrated coil (small arrowhead). (C) Proximal M3 segment coil migration (small arrow) can be seen in this posteroanterior (PA) view, with the ERIC device deployed (small arrowhead), with the ACOA aneurysm already coiled (big arrow). (D) Normal PA angiographic run demonstrating absence of the migrated coil and no aneurysm remnant. ACoA, anterior communicating artery; ERIC, Embolus Retriever with Interlinked Cages.
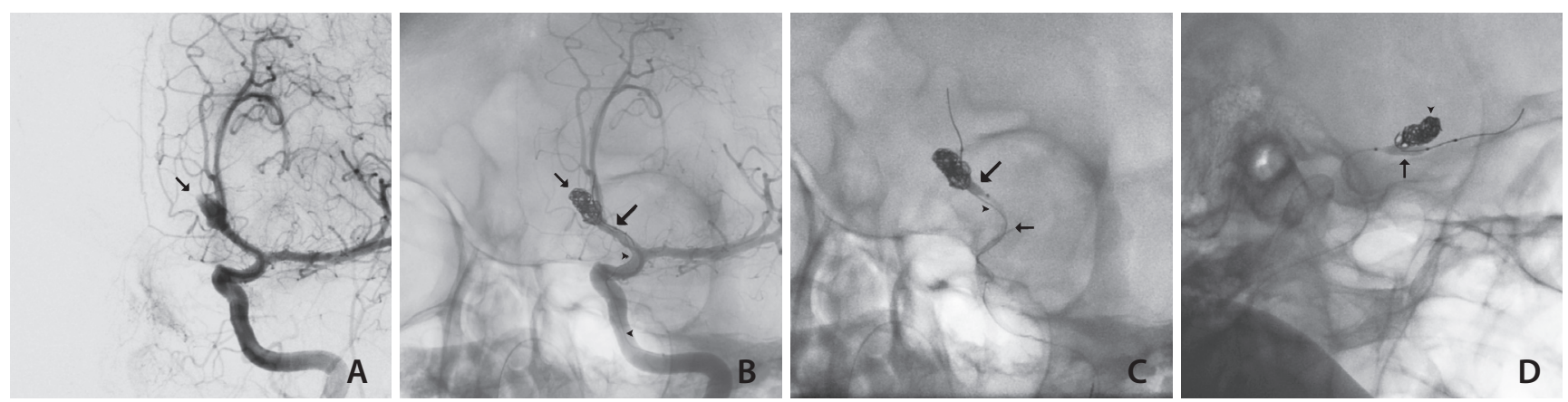

Fig. 3. (A) Ruptured ACoA aneurysm prior to embolization (arrow). (B) Partially coiled aneurysm (small arrow), with a proximally migrated coil (small arrowheads) and a balloon microcatheter (big arrow) covering the aneurysm neck. (C) ERIC device deployed (small arrow) during retrieval maneuver while inflating the balloon (big arrow) to maintain the rest of the coils inside the aneurysm. (D) Post-retrieval image with coil packing integrity maintained (small arrowhead) and the balloon still partially inflated (big arrow). ACoA, anterior communicating artery; ERIC, Embolus Retriever with Interlinked Cages. 


\section{Case 2}

A elderly patient with SAH-FISHER IV, H\&H V, and WFNS V was diagnosed with a ruptured ACoA aneurysm, and emergent embolization was performed (Fig. 3A). During the last coil detachment, we had to try at least 3 times because it would not detach from the pusher. In the end, after detachment, we observed a proximal migration to terminal internal carotid artery (TICA) of this last coil (Fig. 3B). After administering a loading dose of IV aspirin and an unsuccessful attempt at retrieval with a $4.5 \times 30 \mathrm{~mm}$ Aperio ${ }^{\oplus}$ stentriever, a $6 \times 44$ Eric device was deployed through a 0.017 inch microcatheter (Stryker ${ }^{\circledast}$ SL-10), successfully retrieving the coil in 1 pass (Fig. 3C, D).

As presented, in both cases the coil was successfully retrieved with the ERIC device ${ }^{\circledast}$ in 1 pass, after failure of other devices and strategies. This represents a first-pass success of the ED for retrieving a migrated coil in our series.

\section{Flow-model Analysis}

During the in vitro analysis, the detached coil was retrieved in a single pass with the ERIC device ${ }^{\circledast}$ (Fig. 4A, B). On the other hand, while the Trevo ${ }^{\oplus}$ SR did not move the coil during both retrieval attempts (Fig. 4C, D), the EmboTrap ${ }^{\oplus}$ did interact with it, proximally displacing though not fully retrieving it, and so was also unsuccessful in extracting the coil after 2 attempts (Fig. 4E, F).
The detached coil was retrieved twice consistently in 1 pass with the use of the ED, whereas with the other 2 SR, the coil was not retrieved (Table 1).

\section{DISCUSSION}

Thromboembolic events represent the most feared complications associated with endovascular treatment of brain aneurysms, ${ }^{3}$ and migration of detachable coils during embolization significantly contributes to this risk. In addition, the coil may migrate further into smaller vessels, producing flow limitation, or worse it may stretch and fracture, creating a thrombogenic nidus leading to a parent vessel occlusion or distal shower of microemboli material, which may result in a large territory infarct or even death. Although most case series report a low incidence of $2-6 \%$ of coil migration, ${ }^{4}$ the potentially devastating consequences associated with this complication require the development of an effective and secure maneuver to retrieve the displaced coil.

Microsnares and the Alligator device ${ }^{\varpi}$ were specifically developed for the retrieval of foreign bodies from intracranial vessels, ${ }^{9}$ but the difficulty and potential complications associated with the use of snares and the production stop of the Alligator have rendered these devices obsolete. On the other hand, use of the Merci retriever ${ }^{6}$ and guidewires ${ }^{7}$ have also
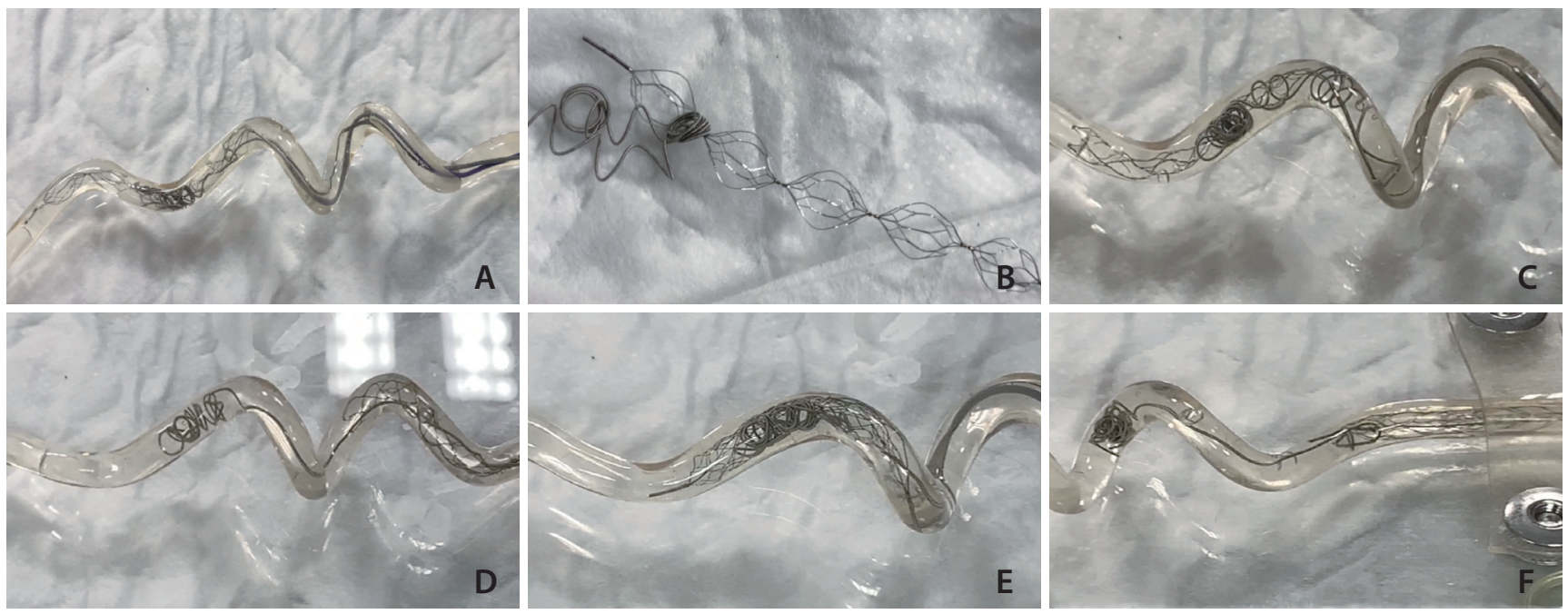

Fig. 4. (A) ERIC opened inside the flow model at the level of the migrated coil before the retrieval attempt. (B) Coil was retrieved from the flow model and found around one of the interlinked cages of the device. (C) Closed cell SR (Trevo; Stryker, Kalamazoo, MI, USA) positioned around the detached coil. (D) Coil remained in place after retrieval, unaffected after the closed cell SR retrieval attempt. (E) EmboTrap positioned in contact with the detached coil. (F) Attempt made with the articulated stent resulted in partial displacement of the coil (coil interaction), but not complete retrieval. ERIC, Embolus Retriever with Interlinked Cages; SR, stent retrievers. 
been described in small case series, but the unavailability of the first and unpredictability associated with the second are also a limitation for their use.

Most publications regarding the use of stent retrievers are small case series or case reports like ours. Leslie-Mazwi et al. ${ }^{5}$ reported the use of Solitaire and Catch Plus stent retrievers in a series of 14 patients, and although successful in all cases, only in 6 showed the coil retrieved with a single pass, with 1 patient requiring 7 passes. Zhou et al. ${ }^{10}$ presented a case series of 7 patients with dislodged neurovascular devices, 5 of which presented a coil migration that was successfully retrieved with a stentriever, although no mention was made of the device construction, with more emphasis made on the technique of securing the coil between the device and the microcatheter, as a way of ensuring the retrieval.

Kabbani et al. ${ }^{11}$ reports a case of a prematurely detached coil migrated into the left pericallosal artery, in which after previous failed attempts with Microsnares, a Trevo ProVue ${ }^{\oplus}$ was used to successfully retrieve the coil in 2 passes. Similarly, Nas et al. ${ }^{12}$ presented another case of a partially protruding coil being retrieved with a Solitaire ${ }^{\circledR}$ device after 3 passes, with no mention of the device construction in its ability to successfully retrieve the coil. Amuluru et al. ${ }^{13}$, on the other hand, discussed the characteristics of stentrievers and the construction and the superiority of these devices over snares or other retrieval technologies, and even proposed that the use of a large Solitaire ${ }^{\circledast}$ in a small-caliber vessel would theoretically allow multiple struts crossings in a better coil engagement. The authors reflected on the problem of crossing the dislodged coil with a microcatheter and the possibility of displacing it further into smaller vessels, though they did not comment on the possibility of using smaller microcatheters to reduce that problem.

Finally, Nikoubashman et al. ${ }^{14}$ presented a study in an animal model in which the Trevo Provue stentriever was used to perform 148 extractions, with a success rate of $72 \%$, and they described a retrieval technique in which the coil was trapped within the stent by partially re-sheathing it, thus locking parts of the coil inside, and achieving a 99\% success rate with this technique. In our series, we did not try this retrieval technique, but it should perform equally or even better with the ERIC device due to its multicage configuration. In our opinion, in contrast with other tubular design stentrievers, the specific design of the ERIC device could theoretically allow a better coil trapping between any of the cages (Fig. 4B), increasing the probability of coil retrieval. Also, the 0.017 inch microcatheter profile could minimize the risk of coil distal displacement in comparison with a 0.021 microcatheter during the rescue maneuvers.

On the other hand, Simgen et al. ${ }^{15}$ reports on another animal model in which different stentrievers were used for volume coils retrieval, and the results reported inferiority of ERIC in comparison with the other 3 stent retrievers. Nevertheless, it should be considered that the difference in coil size may play a role in this result, which may not be easily extrapolated to a regular 0.010 coil retrieval.

The ERIC device has been compared with other stentrievers for thrombectomy, showing equivalent angiographic and clinical results to other devices, albeit with a higher rate of complete recanalization (modified thrombolysis in cerebral infarction scale 3), but it has never been described as an alternative for coil retrieval before. ${ }^{16}$

Edwards et al. ${ }^{17}$ reported antiplatelet medication as a useful tool in managing a coil prolapse in some patients as a sufficient way to avoid thromboembolic complications. However, the authors reported specifically on the management of grade I prolapse, not complete coil migration or a high-grade protrusion. On the other hand, the management should not rely solely on the antiplatelet therapy for our cases. Therefore, we used a loading dose of IV aspirin when the complication was observed and then retrieved the coil.

In our series, the use of an ERIC device was associated with a single pass success for recapturing a migrated coil, and its behavior during in vitro testing was superior to other devices, even though the trapping technique was not used, and the stents were retrieved at maximum opening. Another popular segmented device, the EmboTrap, did not provide the same results as the ERIC. It was probably due to a difference in the cage morphology.

This study has inherent limitations. First, it is a small case series with no control population analysis for comparison. Considering the small incidence of these complications, further studies with multicenter data would be needed. Second, the flow-model analysis lacks a full comparison with other stentrievers, specifically the Solitaire stentriever, a popular device even in this setting. However, our goal was to primarily analyze the difference between using a segmented stentriever and a tubular one. For this purpose, we thought that the Trevo stentriever is sufficient to represent the segmented stentriever. Third, the trapping technique, different coils of various sizes, different anatomical sites, and more attempts per device have not been tested, and they will be 
considered in further research. Finally, despite the promising results of our report and current data, the superiority of ERIC over other stentrievers has not been proven, thus requiring larger case series.

Despite all this, to our knowledge, this is the first time the ERIC device has been described as a useful tool for recapturing a migrated coil, and after an analysis and review of the cases and in vitro models, we consider it to be an good device for coil migration management, since the multicage configuration and low profile ( 0.017 inch compatible) allows for a more stable coil trapping, even in distal vessels.

\section{CONCLUSION}

In our experience, the use of the ERIC device may be superior to the classical stentrievers as a bailout strategy for migrated coil retrieval during aneurysm embolization.

\section{Fund}

None.

\section{Ethics Statement}

Our institutional review board (CEIm ÁREA DE SALUD VALLADOLID ESTE) approved this study, and the informed consent was waived. Since the consent for publication was not available for the patients mentioned in the figures, the patient's information was anonymized by removing the sex and specific age.

\section{Conflicts of Interest}

MSA consultant of Medtronic and Balt. JGF consultant of Medtronic and Balt. MMG consultant Medtronic, Balt, Stryker and Tegus Medical.

No other authors have any conflict of interest to disclose.

\section{Author Contributions}

Study concept and design: MSA and MMG. Acquisition of data: MSA, JGF, and MMG. Analysis and interpretation of data: MSA, MMG, and JGF. Drafting of the manuscript: MSA. Critical revision of the manuscript for important intellectual content: MSA, JGF, PJA, LNM, CRA, and MMG. Administrative, technical, and material support: MSA. Study supervision: MMG.

\section{ORCID}

Miguel Schüller-Arteaga: https://orcid.org/0000-0003-3351-668X
Jorge Galván-Fernández: https://orcid.org/0000-0001-9703-0094

Paloma Jiménez-Arribas: https://orcid.org/0000-0003-4536-6260 Leonor Nogales-Martin: https://orcid.org/0000-0003-2736-3760 Carlos Rodríguez-Arias: https://orcid.org/0000-0002-4787-9839 Mario Martínez-Galdámez: https://orcid.org/0000-0002-8024-4712

\section{REFERENCES}

1. Molyneux A, Kerr R, Stratton I, Sandercock P, Clarke M, Shrimpton J, et al.; International Subarachnoid Aneurysm Trial (ISAT) Collaborative Group. International Subarachnoid Aneurysm Trial (ISAT) of neurosurgical clipping versus endovascular coiling in 2143 patients with ruptured intracranial aneurysms: a randomised trial. Lancet 2002;360:1267-1274

2. Bradac GB, Bergui M, Stura G, Fontanella M, Daniele D, Gozzoli $L$, et al. Periprocedural morbidity and mortality by endovascular treatment of cerebral aneurysms with GDC: a retrospective 12year experience of a single center. Neurosurg Rev 2007;30:117125; discussion 125-126

3. van Rooij WJ, Sluzewski M, Beute GN, Nijssen PC. Procedural complications of coiling of ruptured intracranial aneurysms: incidence and risk factors in a consecutive series of 681 patients. AJNR Am J Neuroradiol 2006;27:1498-1501

4. Borggrefe J, Behme D, Mpotsaris A, Weber W. Complications associated with cerebral aneurysm morphology in balloon-assisted coil embolization of ruptured and unruptured aneurysms-a single-center analysis of 116 consecutive cases. World Neurosurg 2016;91:483-489

5. Leslie-Mazwi TM, Heddier M, Nordmeyer H, Stauder M, Velasco A, Mosimann PJ, et al. Stent retriever use for retrieval of displaced microcoils: a consecutive case series. AJNR Am J Neuroradiol 2013;34:1996-1999

6. Vora N, Thomas A, Germanwala A, Jovin T, Horowitz M. Retrieval of a displaced detachable coil and intracranial stent with an $L 5$ Merci Retriever during endovascular embolization of an intracranial aneurysm. J Neuroimaging 2008;18:81-84

7. Lee CY. Use of wire as a snare for endovascular retrieval of displaced or stretched coils: rescue from a technical complication. Neuroradiology 2011;53:31-35

8. Ding D, Liu KC. Management strategies for intraprocedural coil migration during endovascular treatment of intracranial aneurysms. J Neurointerv Surg 2014;6:428-431

9. Henkes H, Lowens S, Preiss H, Reinartz J, Miloslavski E, Kühne D. A new device for endovascular coil retrieval from intracranial vessels: alligator retrieval device. AJNR Am J Neuroradiol 
2006;27:327-329

10. Zhou KZ, Maingard J, Kok HK, Wang J, Barras CD, O'hare A, et al. Endovascular retrieval of dislodged neurovascular devices with a stentriever: case series and technical review. World Neurosurg 2019;123:e661-e669

11. Kabbani MR, Smith A, Leider M. Endovascular coil retrieval using a TrevoProVue stentriever. J Neurointerv Surg 2015;7:e19

12. Nas OF, Kacar E, Kaya A, Erdogan C, Hakyemez B. Retrieval of a dislocated coil and stent-assisted coiling by Solitaire ${ }^{\circledR}$ stent during endovascular treatment of an intracranial aneurysm. Diagn Interv Imaging 2016;97:381-384

13. Amuluru K, Al-Mufti F, Romero CE. Endovascular retrieval of migrated coil within the distal middle cerebral artery using stentriever device. World Neurosurg 2018;117:382-385

14. Nikoubashman O, Pjontek R, Brockmann MA, Tolba R, Wies- mann M. Retrieval of migrated coils with stent retrievers: an animal study. AJNR Am J Neuroradio/ 2015;36:1162-1166

15. Simgen A, Tomori T, Mühl-Benninghaus R, Bomberg H, Yilmaz $U$, Körner $\mathrm{H}$, et al. Retrieval of migrated volume coils using different clot retrievers in a porcine model. Clin Neuroradiol 2018;28:593-600

16. Ducroux C, Renaud N, Bourcier R, Marnat G, Sibon I, Gory B, et al.; ETIS investigators. Embolus Retriever with Interlinked Cages (ERIC) versus conventional stent retrievers for thrombectomy: a propensity score-based analysis. J Neurointerv Surg 2021;13:255260

17. Edwards NJ, Jones WH, Sanzgiri A, Corona J, Dannenbaum M, Chen PR. Antiplatelet therapy for the prevention of peri-coiling thromboembolism in high-risk patients with ruptured intracranial aneurysms. J Neurosurg 2017;127:1326-1332 